\title{
Adsorption/Desorption Characteristics and Simultaneous Enrichment of Orientin, Isoorientin, Vitexin and Isovitexin from Hydrolyzed Oil Palm Leaf Extract Using Macroporous Resins
}

\author{
Mohamad Shazeli Che Zain ${ }^{1}{ }^{(\mathbb{C}}$, Soo Yee Lee ${ }^{1}{ }^{(\mathbb{C}}$, Chian Ying Teo ${ }^{2, *}$ and Khozirah Shaari ${ }^{1, *(\mathbb{C})}$ \\ 1 Natural Medicines and Products Research Laboratory (NaturMeds), Institute of Bioscience, \\ Universiti Putra Malaysia, Serdang 43400, Selangor, Malaysia; shazelizain@gmail.com (M.S.C.Z.); \\ daphne.leesooyee@gmail.com (S.Y.L.) \\ 2 Department of Pharmaceutical Chemistry, School of Pharmacy, International Medical University, \\ Bukit Jalil 57000, Kuala Lumpur, Malaysia \\ * Correspondence: TeoChianYing@imu.edu.my (C.Y.T.); khozirah@yahoo.com.my (K.S.); \\ Tel.: +60-3-27317742 (C.Y.T.); +60-3-8942148 (K.S.)
}

check for updates

Citation: Che Zain, M.S.; Lee, S.Y.; Teo, C.Y.; Shaari, K. Adsorption/ Desorption Characteristics and Simultaneous Enrichment of Orientin, Isoorientin, Vitexin and Isovitexin from Hydrolyzed Oil Palm Leaf Extract Using Macroporous Resins. Processes 2021, 9, 659. https:// doi.org/10.3390/pr9040659

Academic Editor: Zongbi Bao

Received: 12 March 2021

Accepted: 7 April 2021

Published: 9 April 2021

Publisher's Note: MDPI stays neutral with regard to jurisdictional claims in published maps and institutional affiliations.

Copyright: (c) 2021 by the authors. Licensee MDPI, Basel, Switzerland. This article is an open access article distributed under the terms and conditions of the Creative Commons Attribution (CC BY) license (https:// creativecommons.org/licenses/by/ $4.0 /)$.

\begin{abstract}
Oil palm leaves (OPL) containing flavonoid C-glycosides are abundantly generated as oil palm byproducts. The performances of three macroporous resins with different physical and chemical properties for the enrichment of isoorientin, orientin, vitexin, and isovitexin from acidhydrolyzed OPL (OPLAH) extract were screened. The XAD7HP resin exhibited the best sorption capacities for the targeted flavonoid C-glycosides and was thus selected for further evaluation. Static adsorption using the XAD7HP resin under optimal conditions (extract adjusted to $\mathrm{pH}$, shaken at $298 \mathrm{~K}$ for $24 \mathrm{~h}$ ) gave adsorption kinetics that fit well with a pseudo-second-order kinetic model. The adsorption of isoorientin and orientin was well described by Langmuir isotherms, while vitexin and isovitexin fit well with the Freundlich isotherms. Dynamic sorption trials using the column-packed XAD7HP resin produced 55-60-fold enrichment of isovitexin and between 11 and 25 -fold enrichment of isoorientin, vitexin, and orientin using aqueous ethanol. The total flavonoid C-glycoside-enriched fractions (enriched OPLAH) with isoorientin $(247.28-284.18 \mu \mathrm{g} / \mathrm{mg}$ ), orientin

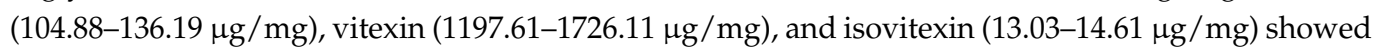
excellent antioxidant free radical scavenging activities compared with their crude extracts, with $\mathrm{IC}_{50}$ values of $6.90-70.63 \mu \mathrm{g} / \mathrm{mL}$ and $44.58-200.00 \mu \mathrm{g} / \mathrm{mL}$, respectively. Hence, this rapid and efficient procedure for the preliminary enrichment of flavonoid C-glycosides by using macroporous resin may have practical value in OPL biomass waste utilization programs to produce high value-added products, particularly in the nutraceuticals, cosmeceuticals, pharmaceuticals, and fine chemicals industries.
\end{abstract}

Keywords: oil palm leaves; total flavonoid C-glycosides; acid hydrolysis; macroporous resin; enrichment; antioxidant free radical scavenging activity

\section{Introduction}

The oil palm (Elaeis guineensis Jacq.) tree was introduced into Malaysia in 1875, with the first oil palm tree plantation established at Tennamaran Estate in Kuala Selangor [1]. Fueled by full support from Malaysian government agricultural diversification initiatives, palm oil plantations expanded tremendously and now cover a large acreage of agricultural land areas [2]. Currently, Malaysia is the second-largest oil palm producer in the world after Indonesia [3]. In fact, the latest statistics show that Malaysia was reaching 20 million tons of crude palm oil production in 2020 [4]. However, in the wake of this massive cultivation, a huge amount of oil palm biomass is generated as agricultural waste. Apart from mesocarp fibers (MF), empty fruit bunches (EFB), and palm kernel shells (PKS) from downstream 
processing in oil palm mills, in parallel, oil palm trunks (OPT), oil palm fronds (OPF), and oil palm leaves (OPL) were also generated, presenting a huge environmental problem if left unutilized [5].

Like many other species in the plant kingdom, OPL byproduct is an excellent source of phytochemicals which could be used for some applications. OPL have in fact been reported to contain bioactive compounds that are responsible for various medicinal properties, such as treating kidney diseases, cancer, cardiovascular diseases, and wounds [6]. A previous study on OPL revealed the presence of both flavonoid $O$ - and $C$-glycosides [7]. In general, flavonoid $C$-glycosides are not widely present in plants, and due to this, they have received less attention in comparison with their O-glycosyl counterparts. Nevertheless, several recent biological and pharmacological studies have shown that flavonoid $C$-glycosides also possess a wide spectrum of biological properties, which include anticancer, hepatoprotective, antioxidant, and antidiabetic properties [8]. Flavonoid C-glycosides differ from flavonoid $\mathrm{O}$-glycosides in that they are more resistant to hydrolysis, since the aglycone is linked to the anomeric carbon of the sugar moiety via an acid-resistant $\mathrm{C}-\mathrm{C}$ bond. Figure 1 shows the structures of four flavonoid C-glycosides of OPL, which include orientin, isoorientin, vitexin, and isovitexin. These flavonoid $C$-glycosides were present in considerable amounts in comparison with other luteolin and apigenin derivatives in OPL [7,9-12]. It is worth noting that the global demand for flavonoids, including flavonoid C-glycosides, is forecasted to reach USD 1.2 billion by 2024 [13]. Therefore, their presence in a widely available and abundant biomass material warrants further investigation into the development of efficient methods for the preparative purification for downstream purposes and applications.

$\mathbf{A}$

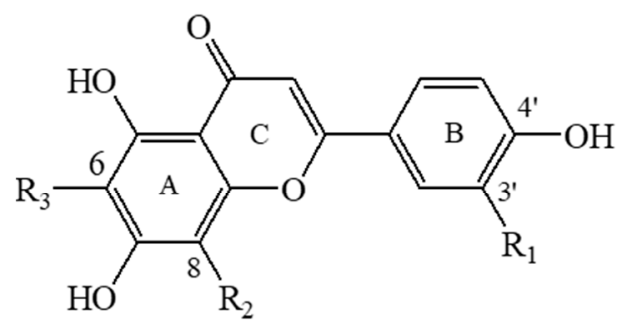<smiles>CC1(C)OC(CO)C(O)C1O</smiles>

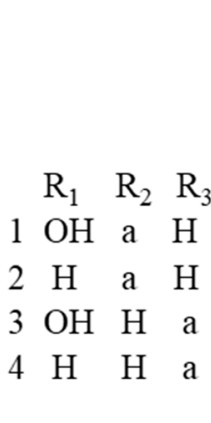

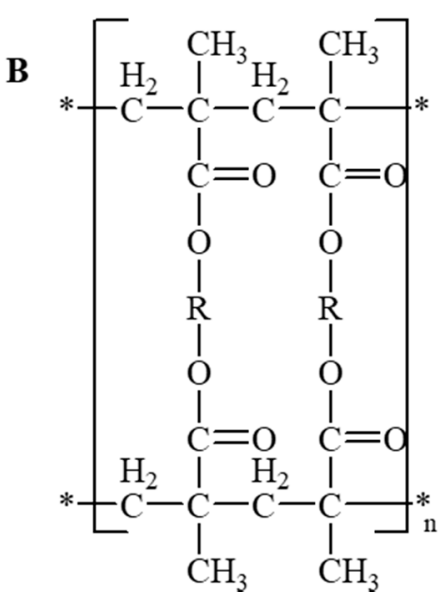

Figure 1. (A) Structures of C-glycosyl flavonoids identified in oil palm leaves (OPL): orientin (1), vitexin (2), isoorientin (3), isovitexin (4). (B) Structure of the XAD7HP resin. $\mathrm{R}=$ polyfunctional aliphatic residue.

Utilization of macroporous resins (MARs) in separating and purifying the flavonoid $\mathrm{C}$-glycosides present in plant extracts has been practiced in recent years. It offers an alternative to conventional methods, which often start with solid-liquid extraction, followed by liquid-liquid extraction and eventually column chromatography [14]. These conventional approaches are not only time-consuming and inefficient, but they also require high consumption of solvents and energy $[15,16]$. The chemical nature of MARs allows them to selectively adsorb through hydrogen bonding and Van der Waals interactions with benzene rings and hydrogen groups present in the molecular structure of the targeted flavonoids [17]. The entrapment of these flavonoids on MARs is due to similarity in their physical and chemical characteristics, such as the appropriate surface area, average pore diameter, and polarity of both the MARs and the targeted flavonoids [18-20]. The high flavonoid sorption capacities made MARs a useful and practical adsorbent to enrich and purify flavonoid C-glycosides from various plants such as Cajanus cajan (L.) Millsp. 
(pegionpea) [19], Ficus microcarpa L.f leaves [20], Abrus mollis (Jigucao) [18], and many others. Additionally, compared with silica gel, which is commonly used as the adsorbent of choice for compound separation, MARs are reusable, fast, simple, and efficient in trapping compounds of interest, particularly flavonoids from various plant materials [18-20].

Previously, we reported the adsorption behavior of the total flavonoids of OPL extract on different macroporous resins [9]. As an extension of this study, we further examine the adsorption and desorption properties of flavonoid C-glycosides, specifically (1) orientin, (2) vitexin, (3) isoorientin, and (4) isovitexin on a selection of MARs. The MARs with the best sorption properties for the target compounds were then used to develop a rapid and efficient method for the enrichment and purification of $C$-glycosyl flavonoids from acid-hydrolyzed OPL (OPLAH) extract. Factors affecting the sorption properties of the individual flavonoids $C$-glycoside were optimized, and their kinetics and isotherms were simultaneously evaluated. The method developed in this study presents an improved process for converting OPL biomass into fine chemicals at a high purity for potential applications.

\section{Materials and Methods}

\subsection{Chemicals and Reagents}

For the selected macroporous resins (MARs), n-(1-naphthyl) ethylenediamine dihydrochloride; quercetin; sodium acetate; sulphanilamide; 1,1-diphenyl-2-picrylhydrazyl (DPPH); and phosphoric acid were purchased from Sigma-Aldrich (St. Louis, MO, USA). Hydrochloric acid $(\mathrm{HCl})$, dimethyl sulfoxide (DMSO), sodium hydroxide $(\mathrm{NaOH})$, formic acid, acetonitrile, and ammonium formate were acquired from Merck (Darmstadt, Germany). Sodium nitroprusside was obtained from Bendosen Laboratory Chemicals (Bendosen, Norway), methanol $(\mathrm{MeOH})$ and ethanol $(\mathrm{EtOH})$ were acquired from R\&R Chemicals (Essex, UK), and aluminum chloride was procured from HmbG Chemicals (Hamburg, Germany). With purities greater than $98.0 \%$, isoorientin, orientin, vitexin, and isovitexin were obtained from Wuhan ChemFaces Biochemical Co., Ltd. (Wuhan, China). Milli-Q ultrapure water (Millipore Lab, Bedford, MA, USA) was used in all experiments.

\subsection{Pretreatment of MARs}

The chemical and physical properties of the selected MARs (XAD7HP, DAX-8, and XAD4) are summarized in Table 1. All MARs were pretreated prior to use to remove residual monomers and porogenic agents, which could be trapped in the pores of the resins during manufacturing. The MARs were soaked in $95 \% \mathrm{EtOH}$ at a 1:20 ratio and washed with deionized water. The resins were then immersed in $1 \mathrm{~mol} / \mathrm{L} \mathrm{NaOH}$ and washed several times with deionized water to remove the base. Subsequently, the resins were subjected to a second immersion in $1 \mathrm{~mol} / \mathrm{L} \mathrm{HCl}$ and then washed thoroughly with deionized water to remove the acid. For each stage of the pretreatment, the resins were allowed to soak for $24 \mathrm{~h}$ before washing. The washed resins were then dried in a drying oven (model 100-800, Memmert, Schwabach, Germany) at $60^{\circ} \mathrm{C}$ until reaching a constant weight.

Table 1. Chemical and physical properties of different macroporous resins (MARs).

\begin{tabular}{cccc}
\hline & XAD7HP & DAX-8 & XAD4 \\
\hline Functional group & Acrylic & Acrylic ester & Styrene-divinylbenzene \\
Particle diameter $(\mathrm{mm})$ & $0.250-0.841$ & $0.250-0.420$ & $0.250-0.841$ \\
Surface area $\left(\mathrm{m}^{2} / \mathrm{g}\right)$ & 380 & 140 & 750 \\
Pore size $(\AA)$ & $300-400$ & 225 & 100 \\
Polarity & Moderate & Moderate & Polar \\
\hline
\end{tabular}




\subsection{Preparation of Crude and Acid-Hydrolyzed Extracts}

Mature OPL were harvested from oil palm trees growing in the University Agricultural Park at the Universiti Putra Malaysia (UPM). A voucher specimen (SK 3332/18) was placed in the mini herbarium of the Institute of Bioscience (IBS) at UPM after the species was authenticated by an appointed botanist. The optimized procedures of preparing crude and acid-hydrolyzed OPL extract were described in our recent publication [10]. Briefly, the powdered OPL was mixed with aqueous $\mathrm{MeOH}$ (4:1 MeOH:water, v:v) and vortex-mixed for $0.5 \mathrm{~min}$ at $3000 \mathrm{~g} / \mathrm{min}$. The mixture was ultrasonicated at a frequency of $40 \mathrm{~Hz}$ for $30 \mathrm{~min}$ at $25^{\circ} \mathrm{C}$.

Subsequently, the crude OPL extract was mixed with distilled water and $6 \mathrm{~mol} / \mathrm{L}$ $\mathrm{HCl}$ in a ratio of 1:10:10 (w:v:v). The mixture was incubated for $45 \mathrm{~min}$ at $95^{\circ} \mathrm{C}$. At $25^{\circ} \mathrm{C}$, $40 \mathrm{~mL} \mathrm{MeOH}$ was added. After centrifuging at $4000 \mathrm{~g} / \mathrm{min}$ for $15 \mathrm{~min}$, the supernatant was separated, vacuum-evaporated to dryness, and then freeze-dried at $0.064 \mathrm{mbar}$ and $-50{ }^{\circ} \mathrm{C}$ using a Labconco ${ }^{\circledR}$ FreeZone Freeze Drier System (Kansas, MO, USA) to yield acid-hydrolyzed OPL extract (OPLAH).

\subsection{UHPLC Analysis of Orientin, Isoorientin, Vitexin, and Isovitexin}

Chromatographic separation was carried out with an ultra-high performance liquid chromatography (UHPLC) system consisting of an Ultimate 3000 LC system (Thermo Scientific $^{\mathrm{TM}}$ Dionex $^{\mathrm{TM}}$ (Sunnyvale, CA, USA) equipped with a photodiode array detector (PDA-3000) scanning from $200 \mathrm{~nm}$ to $600 \mathrm{~nm}$, a thermostatted column compartment, and an autosampler (Exactive ${ }^{\mathrm{TM}}$, Thermo Fisher Scientific, Waltham, MA, USA). An Acquity UPLC $^{\circledR}$ BEH C $_{18}$ column $(2.1 \times 100 \mathrm{~mm}, 1.7 \mu \mathrm{m})$ (Waters, Manchester, UK) was used for analysis. The mobile phase was comprised of solvent $\mathrm{A}$ (water containing $0.1 \%$ formic acid and $0.063 \%$ ammonium formate) and solvent $\mathrm{B}$ (acetonitrile containing $0.1 \%$ formic acid) flowing at $0.30 \mathrm{~mL} / \mathrm{min}$.

The gradient program employed was performed according to the previously reported method $[9,12]$. Briefly, the program was started with $10 \%$ solvent B for $0.6 \mathrm{~min}$, gradually increased to $11.3 \%$ until $1.5 \mathrm{~min}$, maintained isocratically until $5.5 \mathrm{~min}$, and slightly increased to $11.4 \%$ until $8.0 \mathrm{~min}$ and $11.8 \%$ until $8.2 \mathrm{~min}$. Solvent B was further increased to $12 \%$ until $12.0 \mathrm{~min}$ and then decreased to $10 \%$ for $1.0 \mathrm{~min}$ and maintained until $25 \mathrm{~min}$. The column temperature was maintained at $25^{\circ} \mathrm{C}$, and the UV detector was set to a wavelength of $340 \mathrm{~nm}$. Peak identification was based on the retention time and comparison of UV spectra with the respective reference standards. For sample analysis, $5 \mathrm{mg} / \mathrm{mL}$ of each sample solution was prepared and filtered through a $0.22 \mu \mathrm{m}$ membrane filter. A $2 \mu \mathrm{L}$ sample injection volume was used for all sample analysis.

The quantification method was developed and validated based on the following characteristics: specificity, linearity, limit of detection (LOD) and quantification (LOQ), accuracy, repeatability, intermediate precision, and robustness, according to the International Conference on Harmonization (ICH) guidelines [21]. The full information with regard to method validation has been recently published [22]. Briefly, the developed method displayed good calibration curves with linearity $\left(R^{2}=0.999\right)$ in the ranges of $16-500 \mu \mathrm{g} / \mathrm{mL}$ for isoorientin, $31-800 \mu \mathrm{g} / \mathrm{mL}$ for orientin, $47-1500 \mu \mathrm{g} / \mathrm{mL}$ for vitexin, and $16-500 \mu \mathrm{g} / \mathrm{mL}$ for isovitexin. In addition, the LODs for isoorientin, orientin, vitexin and isovitexin were 17.99, 30.22, 80.63 , and $17.69 \mu \mathrm{g} / \mathrm{mL}$, respectively while the LOQs for these compounds were 54.52 , $91.58,244.35$, and $53.61 \mu \mathrm{g} / \mathrm{mL}$, respectively. The recovery percentages were between $95 \%$ and $105 \%$ for all tested compounds, while for the inter- and intraday precisions, the relative standard deviation (RSD) values were found to be below $5 \%$. For robustness, the chromatographic conditions, such as the detected changes in wavelength, column temperature, and sample stability showed insignificant changes, as indicated by $t$-test results $(p>0.05)$.

\subsection{Preliminary Selection Macroporous Resin as an Effective Adsorbent}

The static adsorption capacities of the resins were first screened to select the best resin for flavonoid enrichment. An accurately weighed amount $(0.1 \mathrm{~g})$ of each of the 
pretreated resins was transferred into $15 \mathrm{~mL}$ centrifuge tubes. A $5 \mathrm{~mL}$ aliquot of OPLAH was then added into the tubes. These centrifuge tubes were capped, placed horizontally, and taped tightly in an orbital shaker (Wisube WIG-10RL Precise Shaking Incubator, Wisd Laboratory Instruments, Wertheim, Germany). The mixture was shaken for $24 \mathrm{~h}$ at $298 \mathrm{~K}$ with an agitation speed of $150 \mathrm{~g} / \mathrm{min}$ to reach adsorption equilibrium. The filtrates were then analyzed by UHPLC. To desorb the flavonoid C-glycosides from the resins, $5 \mathrm{~mL}$ of $95 \% \mathrm{EtOH}$ was added into each tube, and the mixing was repeated using the same conditions, followed by filtering and the filtrates being analyzed by UHPLC. Three individual experiments were performed. Selection of the optimal MAR for use in subsequent studies was made based on the adsorption and desorption capacities of each MAR.

\subsection{Optimization of Sorption Conditions Using Batch Adsorption Tests}

In the present study, the four main operating parameters of temperature, $\mathrm{pH}$, equilibrium time point, and initial concentration were optimized. The optimum conditions for the adsorption of flavonoid C-glycosides from OPLAH were performed using batch adsorption tests, where the $15 \mathrm{~mL}$ OPLAH solution was mixed with a selected adsorbent $(0.3 \mathrm{~g})$ and subjected to continuous agitation using an orbital shaker with a agitation speed of $150 \mathrm{~g} / \mathrm{min}$. All experiments were carried out in triplicate. The optimal conditions were selected based on the quantification of orientin, isoorientin, vitexin, and isovitexin using a developed and validated UHPLC-UV/PDA method. Simultaneously, sorption behaviors such as the kinetics and isotherm were assessed.

To select a suitable sorption temperature, the adsorption and desorption were performed at different oscillation temperatures $(298 \mathrm{~K}, 308 \mathrm{~K}$, and $318 \mathrm{~K})$. The OPLAH solution was adjusted to a $\mathrm{pH}$ of 5, and the mixture was then agitated for $24 \mathrm{~h}$. EtOH (95\%) was used as a desorbing solvent.

To optimize the $\mathrm{pH}$ solution of the OPLAH, three different $\mathrm{pHs}(5,7$, and 9) were adjusted with $1 \mathrm{~mol} / \mathrm{L} \mathrm{HCl}$ or $1 \mathrm{~mol} / \mathrm{L} \mathrm{NaOH}$. Concurrently, the equilibrium time point was monitored by withdrawing an aliquot of supernatant at $0,15,30,60,120,180,240,300$, 360,480 , and $1440 \mathrm{~min}$. The adsorption kinetics curves for the target flavonoid C-glycosides on the XAD7HP resin were constructed. The kinetic data were subjected to two common kinetic models_pseudo-first-order [23] and pseudo-second-order models [24]—and one particle diffusion kinetic model [25].

To optimize the suitable initial concentration, different OPLAH concentrations with a known amount of target flavonoid C-glycosides were prepared, whereby the concentrations of isoorientin, orientin, vitexin, and isovitexin, were in ranges of $1.62-45.12 \mu \mathrm{g} / \mathrm{mL}$, 12.64-89.76 $\mu \mathrm{g} / \mathrm{mL}, 66.76-863.22 \mu \mathrm{g} / \mathrm{mL}$ and 1.00-12.06 $\mu \mathrm{g} / \mathrm{mL}$, respectively. The OPLAH solution was adjusted to the optimized $\mathrm{pH}$ and temperature. Simultaneously, the isotherm data was subjected to two well-known theoretical isotherm models: the Langmuir [26] and Freundlich models [27]. The $R_{L}$ is a dimensionless constant that was applied to signify the important equilibrium parameter of the Langmuir isotherm [28].

\subsection{Dynamic Sorption Experiments on the Chromatography Column}

The dynamic sorption procedure was carried out according to our recent publication [9] with modifications. By using a $2.5 \mathrm{~cm} \times 46 \mathrm{~cm}$ glass column wet-packed with $4.4 \mathrm{~g}$ of dried XAD7HP resin, the dynamic adsorption and desorption experiments were performed. The resin bed volume (BV) was kept at $200 \mathrm{~mL}$. The $750 \mathrm{mg}$ of OPLAH was mixed with $150 \mathrm{~mL}$ of deionized water to form a $5 \mathrm{mg} / \mathrm{mL}$ solution. The $\mathrm{pH}$ of the filtered solution was adjusted to $\mathrm{pH}$, applied to the glass column, and allowed to elute at a flow rate of $0.3 \mathrm{~mL} / \mathrm{min}$. The eluates were collected every $10 \mathrm{~mL}$ for UHPLC analysis. The $5 \%$ breakthrough and $95 \%$ saturation points were set based on the final to the initial concentration ratio $\left(\mathrm{C} / \mathrm{C}_{\mathrm{o}}\right)$ of each flavonoid $\mathrm{C}$-glycoside. After reaching the saturation point, the desorption process proceeded by first washing the column with $30 \mathrm{~mL}$ of deionized water to remove the residue and eluting with $\mathrm{EtOH}$, which acted as desorbing solvent, at a flow 
rate of $0.3 \mathrm{~min} / \mathrm{mL}$. The eluates were collected every $10 \mathrm{~mL}$ for UHPLC analysis. All dynamic sorption experiments were carried out in triplicate and at an optimized temperature. The breakthrough and desorption curves were plotted to determine the breakthrough and saturation points.

To select a suitable ethanol concentration for optimal desorption, both the isocratic and gradient elution modes were performed. For the isocratic mode, upon reaching equilibrium, $20 \% \mathrm{EtOH}$ was loaded to elute the adsorbed flavonoids. The experiment was repeated by using different EtOH concentrations (40\%, 60\%, 80\%, and 95\%). For the gradient elution mode, a separate set of experiments was performed by eluting the adsorbed flavonoids using different EtOH concentrations of $20 \%, 40 \%, 60 \%, 80 \%$, and $95 \%$. The collected fractions for both modes were concentrated using a rotary evaporator, freeze-dried, weighed, and subjected to UHPLC analysis.

\subsection{Adsorption and Desorption Capacity, Kinetics, and Isotherm Model Equations}

Adsorption capacity:

$$
q_{e}=\frac{C_{o}-C_{e}}{W} \times V
$$

Desorption capacity:

$$
q_{d}=\frac{C_{d} V_{d}}{W}
$$

Pseudo-first-order:

$$
\ln \left(q_{e}-q_{t}\right)=-k_{1} t+\ln q_{e}
$$

Pseudo-second-order:

$$
\frac{t}{q_{t}}=\frac{1}{k_{2} q_{e}^{2}}+\frac{t}{q_{e}}
$$

Intraparticle diffusion:

$$
q_{t}=k_{p} \cdot t^{\frac{1}{2}}+C
$$

Langmuir:

$$
\frac{C_{e}}{q_{e}}=\frac{K_{L}}{q_{m}}+\frac{C_{e}}{q_{m}}
$$

Freundlich:

$$
q_{e}=K_{f} C_{e^{\frac{1}{n}}}
$$

$R_{L}$ :

$$
R_{L}=\frac{1}{1+K_{L} C_{o}}
$$

where $q_{e}, q_{d}, q_{m}$, and $q_{t}$ are the adsorption capacity, desorption capacity, maximum adsorption capacity, and adsorption capacity at different contact times $(t, \mathrm{~min})$, respectively, which are stated as $\mathrm{mg} / \mathrm{g}$ of dry resin; $C_{o}$ and $C_{e}$, are the initial and equilibrium sample concentrations, respectively, while $C_{d}$ is the sample concentration in the desorption solution (these concentrations are measured in $\mathrm{mg} / \mathrm{mL}$ ); $V, W$, and $C$ are the volume of the initial sample solution $(\mathrm{mL})$, weight of the resin $(\mathrm{g})$, and the constant representing the boundary layer diffusion effects $(\mathrm{mg} / \mathrm{g})$, respectively; $k_{1}, k_{2}$, and $k_{p}$ are the $p s e u d o$-first-order rate constant $(1 / \mathrm{min})$, pseudo-second-order rate constant $(\mathrm{g} / \mathrm{mg}$.min), and particle diffusion rate constant $\left(\mathrm{mg} / \mathrm{g} \cdot \mathrm{min}^{1 / 2}\right)$, respectively; $K_{L}$ is the Langmuir constant $(\mathrm{mg} / \mathrm{mL})$, and $K_{f}$ and $1 / \mathrm{n}$ are the Freundlich constant $\left((\mathrm{mg} / \mathrm{g})(\mathrm{mL} / \mathrm{mg})^{1 / \mathrm{n}}\right)$.

\subsection{Determination of the Total Flavonoid Content and Antioxidant Free Radical Scavenging Activities}

Evaluation of the total flavonoid content (TFC) was conducted using an aluminum chloride complex colorimetric assay [9]. Briefly, a $125 \mu \mathrm{L}$ aliquot of $0.1 \mathrm{mg} / \mathrm{mL}$ OPL extract was transferred into a $2 \mathrm{~mL}$ microcentrifuge tube. Subsequently, $375 \mu \mathrm{L}$ of $95 \% \mathrm{EtOH}, 25 \mu \mathrm{L}$ of a $10 \%$ aluminum chloride solution, $25 \mu \mathrm{L}$ of a $1 \mathrm{~mol} / \mathrm{L}$ sodium acetate solution, and 
$700 \mu \mathrm{L}$ of distilled water were added, and the mixture was vortex-mixed (Vortex IKA MS 3 Basic, Selangor, Malaysia). A $200 \mu \mathrm{L}$ aliquot of the mixture was then transferred into 96 well plates and incubated for $40 \mathrm{~min}$ at $25^{\circ} \mathrm{C}$, and the absorbance was recorded at $415 \mathrm{~nm}$ on a Tecan Infinite F200 Pro plate reader (Tecan Group Ltd., Männedorf, Switzerland). All tests were performed in triplicate. The TFC values were expressed in milligrams of quercetin equivalents per gram of extract (mg QCE/g extract).

The antioxidant assays, such as 1,1-diphenyl-2-picrylhydrazyl (DPPH), and nitric oxide (NO)-free radical scavenging activities were carried out according to the previous report [9]. The samples were prepared at $1000 \mu \mathrm{g} / \mathrm{mL}$ as a stock solution and serially diluted. For the DPPH assay, aliquots of $50 \mu \mathrm{L}$ of the sample working solution were pipetted into a microtiter well plate, and each was added with $100 \mu \mathrm{L}$ of a $59 \mu \mathrm{g} / \mathrm{mL} \mathrm{DPPH}$ solution. The reaction mixtures were mixed well and incubated in the dark for $30 \mathrm{~min}$, after which their absorbances were recorded at $515 \mathrm{~nm}$. Similarly, for the NO assay, aliquots of $60 \mu \mathrm{L}$ of the test concentrations were pipetted into the microtiter well plate, and each was added with $60 \mu \mathrm{L}$ of a sodium nitroprusside solution. The reaction mixtures were mixed well and incubated for $150 \mathrm{~min}$ at $25^{\circ} \mathrm{C}$. Griess reagent $(60 \mu \mathrm{L})$ was then added to each well, and the absorbance was measured at $550 \mathrm{~nm}$. The scavenging activity (SA) was assessed as $\mathrm{SA} \%=\left[\left(\mathrm{A}_{\mathrm{O}}-\mathrm{A}_{\mathrm{S}}\right) / \mathrm{A}_{\mathrm{O}}\right] \times 100 \%$, where $\mathrm{A}_{\mathrm{O}}$ and $\mathrm{A}_{\mathrm{S}}$ are the absorbances of the blank and test sample, respectively. In this experiment, quercetin was used as a positive control. The experiment was carried out in triplicate, and the results were expressed as $\mathrm{IC}_{50}$ values in $\mu \mathrm{g} / \mathrm{mL}$.

\subsection{Statistical Analysis}

The InStat V2.02 statistical package (GraphPad Software, San Diego, CA, USA) and Minitab statistical software (Version 16, Minitab Inc., State College, PA, USA) were employed for all data analyses. For analysis of significance differences, one-way analysis of variance (ANOVA) done by Tukey's test was employed. The significant level was determined at $p<0.05$. All data are shown as the mean of three replicates $(n=3)$.

\section{Results and Discussion}

\subsection{Adsorption and Desorption Capacities of Selected MARs}

The sorption capacities of the three MARs (XAD7HP, DAX-8, and XAD4) for the four flavonoid C-glycosides in OPLAH are shown in Figure 2. The adsorption capacity of the XAD7HP resin was $7.62 \mathrm{mg} / \mathrm{g}$, which was considerably higher than those of DAX-8 and XAD4 at $7.41 \mathrm{mg} / \mathrm{g}$ and $0.92 \mathrm{mg} / \mathrm{g}$, respectively. With a value of $6.73 \mathrm{mg} / \mathrm{g}$, the desorption capacity of the XAD7HP resin was also higher than that of DAX-8 at $4.89 \mathrm{mg} / \mathrm{g}$. Meanwhile, no desorption of flavonoid C-glycosides was observed for XAD4. Referring to these data, the XAD7HP resin had the best sorption capacities, demonstrating that an acrylic matrix, moderately polar resin, medium surface area, and large average pore diameter are the most suitable characteristics of MARs for the adsorption and desorption of the major OPLAH flavonoid C-glycosides. The findings are consistent with the previous findings, which reported high sorption capacities of the XAD7HP resin and low sorption capacities for XAD4 for grapefruit polyphenols [29] and oleuropein from olive (Olea europaea) leaves [30]. Therefore, the XAD7HP resin was selected for further evaluation. 

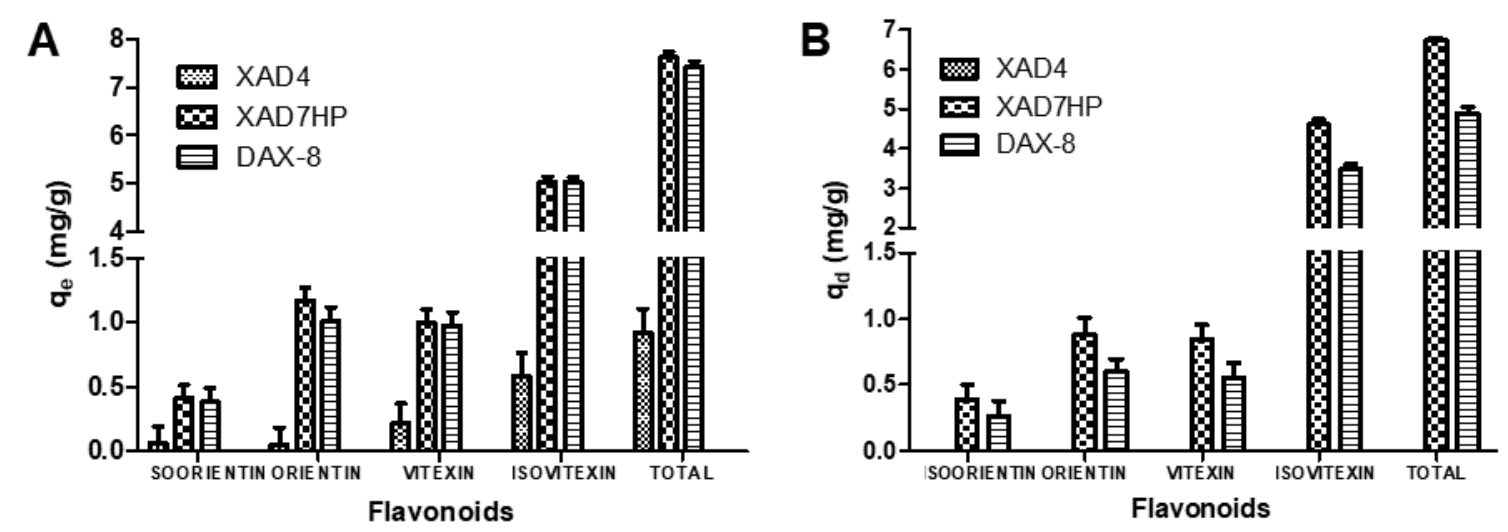

Figure 2. Adsorption (A) and desorption (B) capacities of three different macroporous resins (MARs) for major flavonoid C-glycosides in acid-hydrolized oil palm leaves (OPLAH). Each value is the average reading from three replicates $(n=3)$.

\subsection{Effect of Oscillation Temperatures on the Sorption Capacities}

The oscillation temperature is crucial for the optimum sorption properties of the resins, as the intermolecular forces between the adsorbates and adsorbents could be altered by subjection to a suitable temperature. According to the results shown in Figure 3, there was no significant difference in the adsorption capacity of flavonoid $C$-glycosides at the three different oscillation temperatures. However, the results were different for the desorption capacity, which decreased with an increase in the oscillation temperature. Similar results were reported in a study using MARs to enrich C-glycosyl flavonoids found in trolliflowers and Abrus mollis $[18,31]$. Within the evaluated temperature range, the sorption process is thermopositive [32]. Hence, the optimal oscillation temperature selected was $298 \mathrm{~K}$, due to it demonstrating the highest adsorption and desorption capacities for flavonoid C-glycosides.
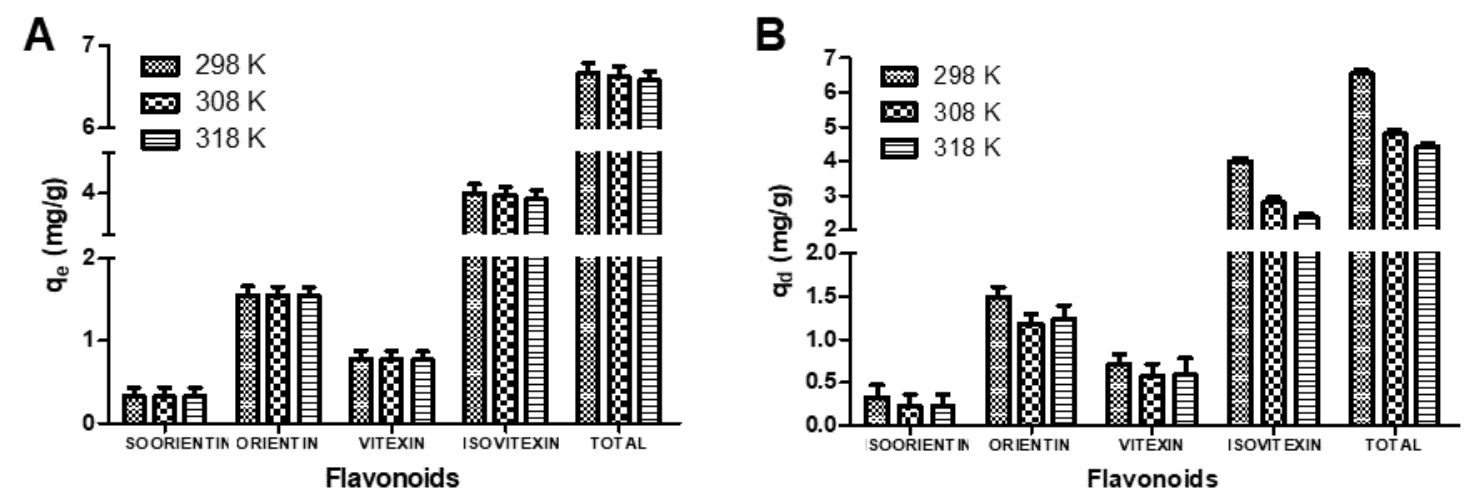

Figure 3. Adsorption (A) and desorption (B) capacities of XAD7HP resin for major flavonoid C-glycosides in OPLAH at three different temperatures. Each value is the average reading from three replicates $(n=3)$.

\subsection{Adsorption Kinetics of the XAD7HP Resin}

The $\mathrm{pH}$ is a factor affecting the ionization capability of certain compounds in the solvent, which ultimately influences their adsorption affinity. Hence, it is vital to perform the sorption at the right $\mathrm{pH}$ [33]. Figure 4 shows that the adsorption capacities $\left(q_{e}\right)$ of the $\mathrm{XAD7HP}$ resin for isoorientin, orientin, vitexin, and isovitexin were higher at a $\mathrm{pH}$ of 5 than at $\mathrm{pHs}$ of 7 and 9. The $q_{e}$ values for isoorientin, orientin, vitexin, and isovitexin decreased linearly as the $\mathrm{pH}$ increased. Based on the observations, hydrogen bonding was deemed to play a significant role in the sorption of the XAD7HP resins. The reduction in adsorption capacity at higher $\mathrm{pH}$ values may have been due to the decrease of hydrogen bonding interactions, caused by the deprotonation of hydroxyl groups in the flavonoid $C$-glycosides 
and the formation of their corresponding anions [19]. On the other hand, a low $\mathrm{pH}$ led to an abundance of hydronium ions at the surface of the resins, which may have enhanced the hydrogen bonding between hydroxyl groups present in the flavonoid $C$-glycosides with the XAD7HP resin, subsequently enhancing the adsorption capacity. The better adsorption capacity of flavonoid $C$-glycosides in acidic rather than basic conditions has been reported previously $[18,19]$.
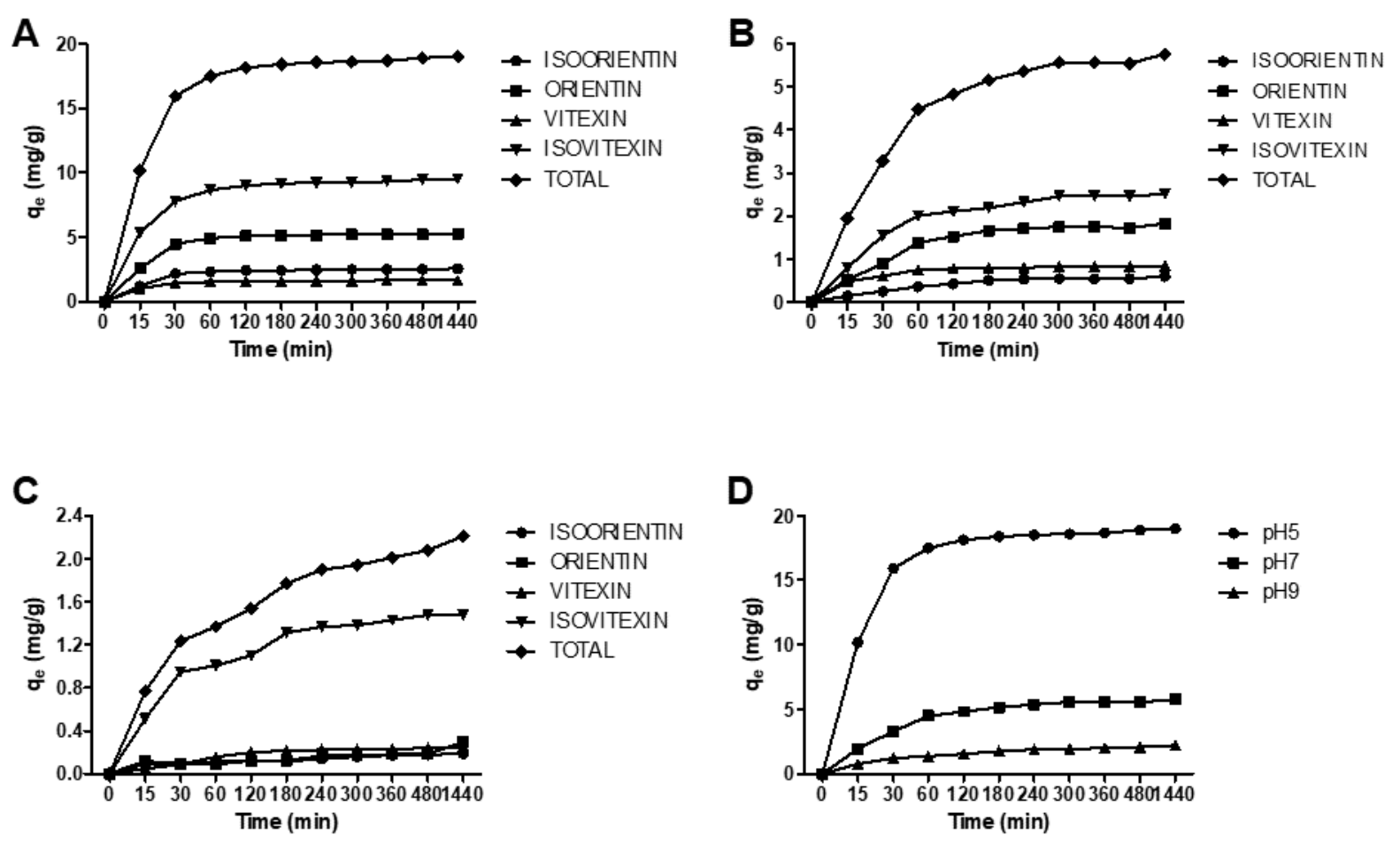

Figure 4. Adsorption kinetic curves of C-glycosyl flavonoids on the XAD7HP resin at pH levels of 5 (A), 7 (B), and 9 (C), and the total of four C-glycosyl flavonoids present in the OPLAH at different $\mathrm{pH}$ levels (D). Each value is the average reading from three replicates $(n=3)$.

The kinetics of adsorption, which explains the solute uptake rate governing the contact time of the sorption reaction, is an important characteristic that defines the sorption efficiency [34]. Hence, the adsorption behavior of the XAD7HP resins could be comprehended by accessing the adsorption kinetics of the flavonoid $C$-glycosides. Figure $4 \mathrm{D}$ presents the adsorption capacity $q_{t}$ versus contact time $(t, \mathrm{~min})$ curves for the XAD7HP resin at different $\mathrm{pH}$ levels at $298 \mathrm{~K}$. Overall, the $q_{t}$ values were enhanced with an increase in time before achieving equilibrium [34]. The equilibrium time for the flavonoid C-glycosides was up to $24 \mathrm{~h}$ on the XAD7HP resin.

There are three commonly suggested kinetics models for adsorption: pseudo-firstorder, $p$ seudo-second-order, and intraparticle diffusion kinetic models [24,25]. Overall, the correlation coefficient $\left(R^{2}\right)$ values revealed that the adsorption of flavonoid $C$-glycosides on the XAD7HP resin fit better to a pseudo-second order kinetic model compared with a pseudo-first-order model. In addition, Table 2 also reveals the multilinear characteristics of adsorption of the flavonoid C-glycosides on the XAD7HP resin, based on the $\mathrm{R}^{2}$ values of the intraparticle diffusion kinetics model. The intraparticle diffusion curves of the XAD7HP resin show poor linear curves over time. By taking a $\mathrm{pH}$ of 5 as an example, the whole process was divided into three major phases: boundary layer diffusion (0-30 $\mathrm{min})$, where the adsorption took place rapidly; a gradual adsorption phase (30-240 $\mathrm{min})$, where the adsorption happened slowly; and finally, the equilibrium phase (240-1440 $\mathrm{min}$ ), where the adsorption reached equilibrium. Similar results were reported in previous studies that showed intraparticle diffusion took place in the adsorption phase [35]. In the present 
study, the whole adsorption phase could not be represented by the particle diffusion kinetic models due to weak $\mathrm{R}^{2}$ values. Nevertheless, it could still explain the adsorption mechanism up to a certain phase [36]. However, it is important to note that different flavonoids, including isoorientin, orientin, vitexin, and isovitexin, will have different ratios of their molecular status to ionic status in various $\mathrm{pH}$ environments. This will probably result in a more complex adsorption mechanism and kinetics, which will require more extensive future studies for greater insights into the mechanisms involved.

Table 2. Pseudo-first-order and pseudo-second-order kinetic equations and the intraparticle diffusion equation for the major C-glycosyl flavonoids in the OPLAH extract on the XAD7HP resin.

\begin{tabular}{|c|c|c|c|c|c|c|c|c|c|c|c|}
\hline \multirow[b]{2}{*}{ Compound } & \multirow[b]{2}{*}{$\mathrm{pH}$} & \multirow{2}{*}{$\begin{array}{c}q_{e}(\exp ) \\
(\mathrm{mg} / \mathrm{g})\end{array}$} & \multicolumn{3}{|c|}{ Pseudo-First Order } & \multicolumn{3}{|c|}{ Pseudo-Second Order } & \multicolumn{3}{|c|}{ IntraParticle Diffusion } \\
\hline & & & $\mathbf{R}^{2}$ & $q_{e}(\mathrm{mg} / \mathrm{g})$ & $\begin{array}{c}k_{1} \\
(1 / \mathrm{min})\end{array}$ & $\mathbf{R}^{2}$ & $q_{e}(\mathrm{mg} / \mathrm{g})$ & $\underset{\text { (g/mg.min) }}{k_{2}}$ & $\mathbf{R}_{2}$ & $C(\mathrm{mg} / \mathrm{g})$ & $\begin{array}{c}k_{p} \\
\left(m g / g . \min ^{1 / 2}\right)\end{array}$ \\
\hline \multirow{3}{*}{ Isoorientin } & 5 & $2.5668^{\mathrm{Aa}}$ & $0.7935^{\mathrm{Aa}}$ & $2.0738^{\mathrm{Aa}}$ & $0.0063^{\mathrm{Aa}}$ & $0.9995^{\mathrm{Aa}}$ & $2.5813^{\mathrm{Aa}}$ & $0.0416^{\mathrm{Aa}}$ & $0.5133^{\mathrm{Aa}}$ & $1.6715^{\mathrm{Aa}}$ & $0.0485^{\mathrm{Aa}}$ \\
\hline & 7 & $0.5916^{\mathrm{Ba}}$ & $0.8134 \mathrm{Ba}$ & 3.1817 Ва & $0.0050 \mathrm{Ba}$ & $0.9971^{\mathrm{Ba}}$ & $0.6007^{\mathrm{Ba}}$ & $0.0403^{\mathrm{Ba}}$ & $0.8506^{\mathrm{Ba}}$ & $0.1468^{\mathrm{Ba}}$ & $0.0218^{\mathrm{Ba}}$ \\
\hline & 9 & $0.1866^{\mathrm{Ca}}$ & $0.9322 \mathrm{Ca}$ & $8.6789^{\mathrm{Ca}}$ & $0.0048^{\mathrm{Ba}}$ & $0.9640 \mathrm{Ca}$ & $0.1851^{\mathrm{Ca}}$ & $0.1102^{\mathrm{Ca}}$ & $0.9196^{\mathrm{Ca}}$ & $0.0701 \mathrm{Ca}$ & $0.0048^{\mathrm{Ca}}$ \\
\hline \multirow{3}{*}{ Orientin } & 5 & $5.2571 \mathrm{Ab}$ & $0.8178^{\mathrm{Ab}}$ & $1.2216^{\mathrm{Aa}}$ & $0.0085^{\mathrm{Ab}}$ & $0.9995^{\mathrm{Aa}}$ & $5.3362 \mathrm{Ab}$ & $0.0238 \mathrm{Ab}$ & $0.5008 \mathrm{Ab}$ & $3.5373^{\mathrm{Ab}}$ & $0.0978 \mathrm{Ab}$ \\
\hline & 7 & $1.8269 \mathrm{Bb}$ & $0.7892^{\mathrm{Bb}}$ & $1.3399^{\mathrm{Bb}}$ & 0.0059 Ва & $0.9980^{\mathrm{Bb}}$ & $1.8643^{\mathrm{Bb}}$ & $0.0195^{\mathrm{Bb}}$ & $0.7597^{\mathrm{Bb}}$ & $0.6503^{\mathrm{Bb}}$ & $0.0613^{\mathrm{Bb}}$ \\
\hline & 9 & $0.2947 \mathrm{Cb}$ & $0.8829^{\mathrm{Cb}}$ & $4.9644 \mathrm{Cb}$ & $0.0014^{\mathrm{Cb}}$ & $0.9641 \mathrm{Ca}$ & $0.2024^{\mathrm{Cb}}$ & $0.0881 \mathrm{Cb}$ & $0.8223^{\mathrm{Cb}}$ & $0.0703 \mathrm{Ca}$ & $0.0054 \mathrm{Ca}$ \\
\hline \multirow{3}{*}{ Vitexin } & 5 & $1.6622 \mathrm{Ac}$ & $0.9158^{\mathrm{Ac}}$ & $3.7371^{\mathrm{Ac}}$ & $0.0090^{\mathrm{Ab}}$ & $0.9999 \mathrm{Aa}$ & $1.6793 \mathrm{Ac}$ & $0.0967^{\mathrm{Ac}}$ & $0.5653^{\mathrm{Ac}}$ & $1.2447^{\mathrm{Ac}}$ & $0.0233^{\mathrm{Ac}}$ \\
\hline & 7 & $0.8356^{\mathrm{Bc}}$ & $0.8718^{\text {Вс }}$ & $5.0799 \mathrm{Bc}$ & $0.0075^{\mathrm{Bb}}$ & 0.9999 Ac & $0.8457 \mathrm{Bc}$ & 0.1137 Вс & $0.8157^{\mathrm{Bc}}$ & $0.3242^{\mathrm{Bc}}$ & $0.0235 \mathrm{Ac}$ \\
\hline & 9 & $0.2481^{C c}$ & $0.9252^{\mathrm{Cc}}$ & $6.8244^{C_{c}}$ & $0.0064^{\mathrm{Cc}}$ & $0.9959^{\mathrm{Bb}}$ & $0.2683^{C c}$ & $0.0703^{\mathrm{Cc}}$ & $0.8229^{\mathrm{Cb}}$ & $0.0518^{\mathrm{Cb}}$ & $0.0101^{\mathrm{Bb}}$ \\
\hline \multirow{3}{*}{ Isovitexin } & 5 & $9.5296 \mathrm{Ad}$ & $0.8763 \mathrm{Ad}$ & $1.9927 \mathrm{Ad}$ & $0.0072 \mathrm{Ac}$ & $0.9998^{\mathrm{Aa}}$ & $9.5877 \mathrm{Ad}$ & $0.0120 \mathrm{Ad}$ & $0.6099 \mathrm{Ad}$ & $6.4869 \mathrm{Ad}$ & $0.1639 \mathrm{Ad}$ \\
\hline & 7 & $2.5159 \mathrm{Bd}$ & $0.8952^{\mathrm{Ad}}$ & $1.1389^{\mathrm{Bd}}$ & $0.0078^{\mathrm{Ab}}$ & $0.9983^{\mathrm{Bb}}$ & $2.6185^{\mathrm{Bd}}$ & $0.0143^{\mathrm{Bd}}$ & $0.7582^{\mathrm{Bb}}$ & $1.0526^{\mathrm{Bd}}$ & $0.0772^{\mathrm{Bd}}$ \\
\hline & 9 & $1.4779^{\mathrm{Cd}}$ & $0.9261 \mathrm{Bc}$ & $1.0830^{\mathrm{Cd}}$ & $0.0101^{\mathrm{Bd}}$ & 0.9974 Cc & $1.5564^{\mathrm{Cd}}$ & $0.0195^{\mathrm{Cd}}$ & 0.8568 Cc & $0.5758^{\mathrm{Cc}}$ & $0.0464^{\mathrm{Cc}}$ \\
\hline
\end{tabular}

Values marked with different uppercase letters $(\mathrm{A}-\mathrm{C})$ indicate a comparison between $\mathrm{pH}$ levels for the same compound. Values marked with different lowercase letters (a-d) indicate a comparison between different compounds for the same $\mathrm{pH}$. Each value is the average reading from three replicates $(n=3)$.

\subsection{Adsorption Isotherms on the XAD7HP Resin}

The adsorption isotherms of flavonoid C-glycosides on XAD7HP resins was performed at room temperature $(298 \mathrm{~K})$ after taking into consideration several factors, including the practicality and energy conservation. Figure S1 shows the isotherm curves for the individual flavonoid C-glycosides in OPLAH. The adsorption behaviors of flavonoid C-glycosides on the XAD7HP resin were further assessed by using two adsorption isotherm equations, namely Langmuir and Freundlich equations. The equations revealed the interaction between the compounds and the resin [37].

The Langmuir and Freundlich parameters are listed in Table 3 . The $\mathrm{R}^{2}$ values of the two models were relatively higher for isoorientin, orientin, and vitexin. With $\mathrm{R}^{2}$ values of 0.9977 and 0.9519 , the adsorption behavior of isoorientin and orientin, respectively, on the XAD7HP resin followed the Langmuir equation. The results indicated that these two compounds displayed monolayer adsorption on the resin, suggesting that orientin and its isomer were in contact with the surface layer of the XAD7HP resin. Meanwhile, vitexin and isovitexin followed the Freundlich equation with $\mathrm{R}^{2}=0.9700$ and 0.8418 , respectively, indicating the adsorption of these isomeric compounds followed a multilayer process wherein the XAD7HP resin accommodated more than one layer for the adsorption of vitexin and its pair to take place. This situation could be related to the molecular structures of vitexin/isovitexin and orientin/isoorientin [38]. As shown in Figure 1A, the molecular sizes of the vitexin and isovitexin structures were relatively smaller compared with orientin and isoorientin, due to the lack of one hydroxyl group $(-\mathrm{OH})$. This could have reduced the steric hindrance in the interaction between vitexin/isovitexin and the XAD7HP resin, thus favoring a multilayer adsorption process. In the Freundlich equation, the value of $R_{L}$ indicates the isotherm shape, which is either unfavorable $\left(R_{L}>1\right)$, linear $\left(R_{L}=1\right)$, favorable $\left(0<R_{L}<1\right)$, or irreversible $\left(R_{L}=0\right)$ [39]. Hence, the present findings showed that the adsorption of the flavonoid $C$-glycosides on the XAD7HP resin was favorable. The $1 / \mathrm{n}$ value is a measure of the adsorption intensity [38]. A value of $1 / \mathrm{n}$ above 2 indicates that adsorption is unlikely to happen [40]. In this study, the $1 / \mathrm{n}$ values of the flavonoid 
C-glycosides were all above 2 , suggesting that the XAD7HP resin was a suitable resin to use for absorbing the flavonoid $C$-glycosides from OPLAH.

Table 3. Langmuir and Freundlich models for the adsorption of OPLAH flavonoid C-glycosides on XAD7HP resin.

\begin{tabular}{|c|c|c|c|c|c|c|c|}
\hline \multirow[b]{2}{*}{ Compound } & \multicolumn{4}{|c|}{ Langmuir Equation } & \multicolumn{3}{|c|}{ Freundlich Equation } \\
\hline & $\mathrm{q}_{\mathrm{m}}(\mathrm{mg} / \mathrm{g})$ & $\mathbf{R}_{1}{ }^{2}$ & $\mathrm{~K}_{\mathrm{L}}(\mathrm{mg} / \mathrm{mL})$ & $R_{L}$ & $1 / n$ & $\begin{array}{c}\mathrm{K}_{\mathrm{f}}((\mathrm{mg} / \mathrm{g}) \\
\left.(\mathrm{mL} / \mathrm{mg})^{1 / n}\right)\end{array}$ & $\mathbf{R}_{2}{ }^{2}$ \\
\hline Isoorientin & $476.1905^{a}$ & $0.9977^{a}$ & $0.2381^{a}$ & $0.2929^{a}$ & $0.3754^{a}$ & $366.090^{a}$ & $0.9260^{a}$ \\
\hline Orientin & $2000.000^{b}$ & $0.9519^{b}$ & $0.6000^{b}$ & $0.0480^{b}$ & $0.3757^{a}$ & $1075.70^{b}$ & $0.9247^{a}$ \\
\hline Vitexin & $50000.00^{c}$ & $0.9624^{c}$ & $30.000^{c}$ & $0.0001^{\mathrm{c}}$ & $0.9538^{b}$ & $1422.10^{c}$ & $0.9700^{b}$ \\
\hline Isovitexin & $204.0816^{\mathrm{d}}$ & $0.5187^{\mathrm{d}}$ & $0.2653^{\mathrm{d}}$ & $0.5120^{\mathrm{d}}$ & $0.4149^{c}$ & $138.930^{d}$ & $0.8418^{c}$ \\
\hline
\end{tabular}

Values marked with different letters $(\mathrm{a}-\mathrm{d})$ indicate a comparison between compounds in each tested parameter. Each value is the average reading from three replicates $(\mathrm{n}=3)$.

\subsection{Dynamic Sorption Properties of the XAD7HP Resin}

On an open column, information of the breakthrough volume is important in estimating the optimum volume of sample-containing compounds of interest that can be loaded onto the column. The breakthrough point was set at $5 \%$ of the inlet concentration [9]. As shown in Figure 5A, the dynamic breakthrough curves on the XAD7HP resin were attained for isoorientin, orientin, vitexin, and isovitexin. The breakthrough volume of isoorientin on the XAD7HP resin was $100 \mathrm{~mL}$, while that of orientin, vitexin, and isovitexin was $30 \mathrm{~mL}$. Meanwhile, the saturation point was defined, at which the exit solute concentration reached $95 \%$ of the inlet concentration [9]. The saturation volume of isoorientin and isovitexin was $150 \mathrm{~mL}$, while that of orientin and vitexin was $130 \mathrm{~mL}$. The dynamic desorption curves for isoorientin, orientin, vitexin, and isovitexin on the XAD7HP resin are shown in Figure 5B,C. The results indicate that at $150 \mathrm{~mL}$, the flavonoids could be sufficiently desorbed and eluted off of the XAD7HP resin column.
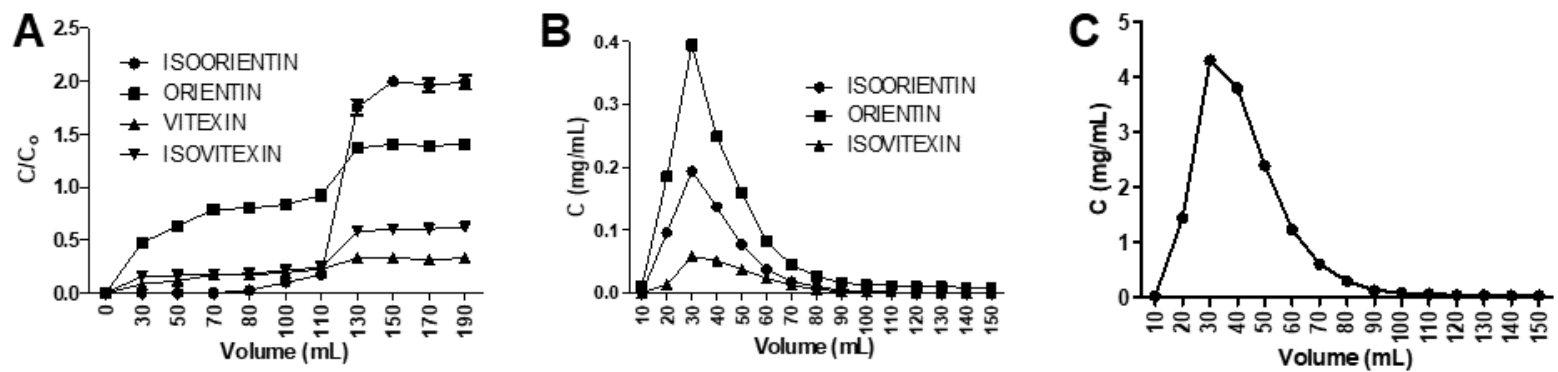

Figure 5. Dynamic breakthrough curves for flavonoid C-glycosides (A) and dynamic desorption curves for isoorientin, orientin, and isovitexin (B) and vitexin (C) in OPLAH on XAD7HP resin. Each value is the average reading from three replicates $(n=3)$.

\subsection{Comparison between Isocratic and Gradient Elution Modes for Optimal Flavonoid C-Glycoside Enrichment}

Enrichment of the OPLAH flavonoid C-glycosides was carried out via isocratic and gradient elution modes by using $\mathrm{EtOH}$ as a desorbing solvent after considering its low cost, ease of removal, and low toxicity [41]. Previous studies have also used EtOH to desorb flavonoid C-glycosides from other various MARs [20,31,42]. The desorbed fractions from the XAD7HP resin were analyzed qualitatively and quantitatively and compared to the original OPLAH. For the isocratic elution mode, a single desorbing solvent system was applied. As shown in Figure 6A, the amount of desorbed flavonoid C-glycosides increased with an increase in the $\mathrm{EtOH}$ concentration (from $20 \%$ to $95 \%$ ). Orientin and vitexin were enriched the most when $80 \% \mathrm{EtOH}$ was used as a single desorbing solvent system, as a further increment to $95 \% \mathrm{EtOH}$ gave insignificant changes. Their respective isomers, isoorientin, and isovitexin were found in the highest fold at $95 \% \mathrm{EtOH}$. Meanwhile, a 
multiple desorbing solvent system was employed in the gradient elution mode. Figure 6B shows that orientin, isoorientin, vitexin, and isovitexin started to desorb rapidly from $20 \%$ to $40 \% \mathrm{EtOH}$ concentrations and started to decrease as the EtOH concentration increased from $60 \%$ to $95 \%$. Thus, the results revealed that the flavonoid C-glycosides found in the OPLAH solution could be desorbed optimally at $95 \%$ and $40 \%$ for the isocratic and gradient desorption techniques, respectively. The desorption of flavonoid $C$-glycosides from the XAD7HP resin into the solvent was attributed to the competition between the interaction of intermolecular forces and dissolution into the solvent used $[9,42]$.

A

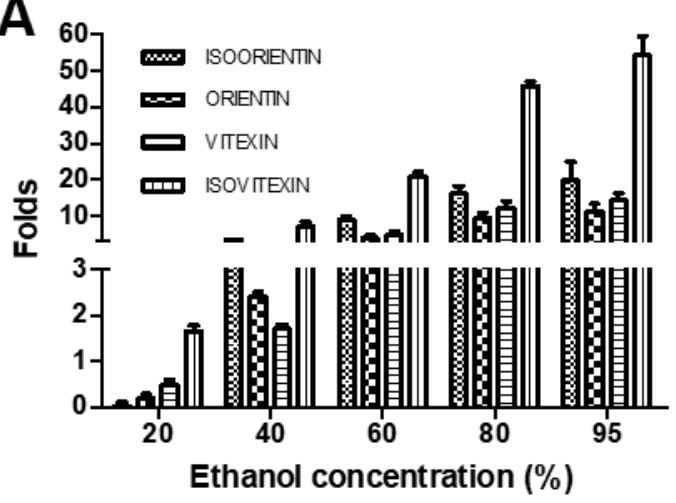

B

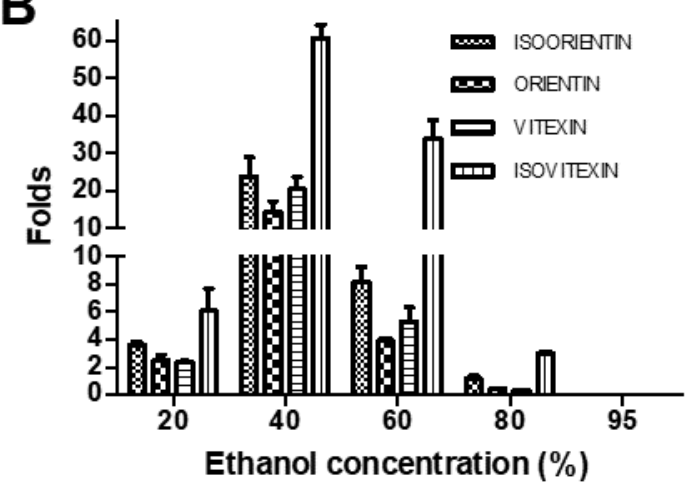

Figure 6. Enrichment of flavonoid C-glycosides from OPLAH by the isocratic elution mode (A) and gradient elution mode (B) on the XAD7HP resin. Each value is the average reading from three replicates $(n=3)$.

The UHPLC chromatograms of the OPLAH and enriched fractions obtained from the isocratic desorption (95\% EtOH) and gradient desorption modes $(40 \% \mathrm{EtOH})$ are shown in Figure S2A. Comparing the chromatogram of the enriched fractions and OPLAH, it could be observed that some impurities present in the original extract were eliminated, while the relative peak areas of the four major flavonoid $C$-glycosides were increased by different degrees. The compounds assigned to peaks 1-4 were confirmed by commercial standards and characterized by liquid chromatography tandem mass spectrometry (LC-MS/MS) (Figure S2B) [10]. The rest of the unassigned peaks have been comprehensively discussed in our previous publications $[7,9,12]$.

Table 4 summarized the quantitative information of the OPLAH and the enriched fractions obtained through the isocratic (with 95\% EtOH) and gradient elution modes (with $40 \% \mathrm{EtOH}$ ). The XAD7HP resin was able to increase the TFC from $88.98 \mathrm{mg}$ QCE/g up to $284.18 \mathrm{mg}$ QCE/g dried extract by 3.2-fold. Among the four flavonoid C-glycosides, at the optimum EtOH concentrations, isovitexin was enriched the most, followed by isoorientin, vitexin, and orientin. As illustrated by Figure 6A for the isocratic elution mode, with 95\% $\mathrm{EtOH}$, isovitexin was enriched almost 55-fold while isoorientin, vitexin, and orientin were enriched by 11 - to 20 -fold. A similar trend was also observed in the gradient elution mode, where at $40 \% \mathrm{EtOH}$, isovitexin was enriched by 60 -fold, isoorientin by 25 -fold, vitexin by 20-fold, and orientin by 15-fold (Figure 6B). 
Table 4. Quantification and free radical scavenging activities of flavonoid C-glycosides in OPLAH, enriched OPLAH fractions and individual compounds.

\begin{tabular}{|c|c|c|c|c|c|c|c|}
\hline \multirow{2}{*}{ Extract or Compound } & \multirow{2}{*}{ TFC (mg QCE/g) } & \multicolumn{4}{|c|}{ Flavonoid $C$-Glycosides $(\mu \mathrm{g} / \mathrm{mg})$} & \multicolumn{2}{|c|}{ Antioxidant Activities $\left(\mathrm{IC}_{50}, \mu \mathrm{g} / \mathrm{mL}\right)$} \\
\hline & & Isoorientin & Orientin & Vitexin & Isovitexin & DPPH & NO \\
\hline OPLAH & $88.98^{\mathrm{a}}$ & $2.34^{\mathrm{a}}$ & $9.35^{\mathrm{a}}$ & $84.11^{\mathrm{a}}$ & $0.25^{\mathrm{a}}$ & $200.00^{a}$ & $44.58^{\mathrm{a}}$ \\
\hline Enriched OPLAH (Isocratic) & $247.28^{b}$ & $46.27^{b}$ & $104.88^{b}$ & $1197.61^{b}$ & $13.03^{\mathrm{b}}$ & $69.16^{b}$ & $6.90^{\mathrm{b}}$ \\
\hline Enriched OPLAH (Gradient) & $284.18^{c}$ & $55.98^{c}$ & $136.19^{c}$ & $1726.11^{\mathrm{c}}$ & $14.61^{\mathrm{b}}$ & $70.63^{\mathrm{b}}$ & $7.32^{\mathrm{b}}$ \\
\hline Isoorientin & & & & & & $14.70^{\mathrm{c}}$ & $68.19^{c}$ \\
\hline Orientin & & & & & & $57.60^{\mathrm{d}}$ & $42.72^{\mathrm{a}}$ \\
\hline Isovitexin & & & & & & $>1000^{\mathrm{e}}$ & $0.73^{\mathrm{d}}$ \\
\hline Vitexin & & & & & & $>1000^{\mathrm{e}}$ & $4.31^{\mathrm{e}}$ \\
\hline
\end{tabular}

Values marked with different letters (a-e) indicate a comparison between OPLAH, enriched OPLAH and individual compounds for each flavonoid content and antioxidant activities. Each value is the average reading from three replicates $(n=3)$.

\subsection{Antioxidant DPPH and NO Free Radical Scavenging Activities}

The antioxidant activities of OPLAH, enriched fractions, and the individual flavonoid $\mathrm{C}$-glycosides were tested using DPPH and NO free radical scavenging assays, and the results are shown in Table 4. The DPPH results revealed that the total flavonoid C-glycoside enriched fractions, obtained using the isocratic and gradient desorption methods, exhibited stronger antioxidant activity, with $\mathrm{IC}_{50}$ values of 69.19 and $70.63 \mu \mathrm{g} / \mathrm{mL}$, respectively. In comparison with the original OPLAH extract, the $\mathrm{IC}_{50}$ value was much lower $(200 \mu \mathrm{g} / \mathrm{mL})$. The results for the NO free radical scavenging assay were also similar, as the enriched fractions exhibited significantly improved activity compared with the original extract. This increase in antioxidant activity indicated the substantial contribution of the enriched flavonoid C-glycoside contents to the overall activity. The results highlighted that both the $\mathrm{DPPH}$ and NO free radical scavenging assays were in good agreement for evaluating the antioxidant activities in both the original and enriched fractions. Previous studies have also reported the positive correlation between the free radical scavenging activity and the presence of high amounts of phenolic constituents [43,44].

The single flavonoid C-glycoside was also assayed for the free radical scavenging activities. Isoorientin with an $\mathrm{IC}_{50}$ value of $14.70 \mu \mathrm{g} / \mathrm{mg}$ exhibited superior DPPH free radical scavenging activity. Its isomer, orientin, was moderately active, with an $\mathrm{IC}_{50}$ value of $57.60 \mu \mathrm{g} / \mathrm{mg}$, while isovitexin and vitexin were weakly active in comparison. The results are in agreement with previous studies that reported vitexin and isovitexin were poor DPPH free radical scavengers $[45,46]$. The structural differences of these flavonoid C-glycosides, such as the position of glycosidic linkages and the number or position of hydroxyl groups at play, will have a significant effect on the bioactivity. For example, the presence of a single hydroxyl group on the B ring of both vitexin and isovitexin may be the reason for their lower activity, in comparison with isoorientin and orientin, which have two hydroxyl groups on the same ring (Figure 1A). Additionally, the weaker activity of isovitexin could be due to steric hindrance associated with glycosylation on C-6, as compared with on C-8 for its isomer, vitexin [47].

Meanwhile, the NO free radical scavenging activity was quite different from the DPPH free radical scavenging activity. All tested apigenin and luteolin $C$-glycosides had good antioxidant activity by showing a great ability to inhibit nitric oxide and superoxide anion at low concentrations. In contrast to the DPPH assay results, isovitexin and vitexin exhibited strong $\mathrm{NO}$ scavenging activity, with $\mathrm{IC}_{50}$ values of 0.73 and $4.31 \mu \mathrm{g} / \mathrm{mg}$, respectively, whereas orientin and isoorientin exhibited weaker values. These results reflect the superiority of isovitexin and vitexin in scavenging nitric oxide and superoxide radicals, which have also been similarly reported in the study of Trigonella foenum graecum L. (fenugreek seeds) [47].

\subsection{Adsorption Mechanisms}

The efficiency of the adsorption and desorption processes primarily relies on the polarity of the MARs. In this experiment, the tested MARs comprised both nonpolar (XAD4) and moderately polar (XAD7HP and DAX-8) resins. The data obtained showed 
that moderately polar resins were more appropriate to entrap and release flavonoid $C$ glycosides from OPL extract. The polarity matching between the extract and resin was related to the multiple interactions between the targeted metabolites and the surface chemistry of the resin $[9,19,29,48]$. Being a nonpolar resin, XAD4, with its smaller pore size, has low wettability and thus is not well-dispersed in an aqueous solution, which explains the low adsorption and no desorption of polar compounds (flavonoid $C$-glycosides (29)). Figure 7 displays the possible interactions between the isoorientin, orientin, vitexin, and isovitexin and the moderately polar XAD7HP resin under acidic conditions. The early part of the study indicated that isovitexin showed the highest adsorption and desorption capacities, followed by vitexin, orientin, and isorientin, suggesting multiple interactions, such as electrostatic interaction, intramolecular and intermolecular hydrogen bonding, ion-dipole interactions, cation-л interaction, and Van der Waals forces of the adsorbent. The XAD7HP resin was more favorable in isovitexin compared with the other compounds (Figure 7). More specifically, the hydroxyl groups at C-4', C-5, or C-7 of the flavones have been reported to be more acidic than the hydroxyl groups attached at other positions [49]. Thus, it is highly likely that the electrostatic interactions of the flavonoids on the surface of the resins could have resulted from the attraction of protons dissociated from the hydroxyl groups at these positions. The hydroxyl groups of the flavonoid C-glycosides can also interact with the resin through the formation of intramolecular and intermolecular hydrogen bonds [50]. Furthermore, polar adsorbates can cause ion-dipole interactions with the polar segment of the moderately polar resin. Other than that, adsorption can also be facilitated by cation- $\pi$ interaction [29], which can occur between hydronium ions $\left(\mathrm{H}_{3} \mathrm{O}^{+}\right)$surrounding the XAD7HP resin and the benzene ring from flavonoids. Lastly, the main driving force for the sorption process on polymeric XAD7HP resin is the existence of Van der Waals forces in an aqueous solvent system. Therefore, based on the high sorption capacities obtained in the study, the efficient simultaneous sorption of isoorientin, orientin, vitexin, and isovitexin was suggested to be substantially contributed by multiple interactions $[9,42]$.

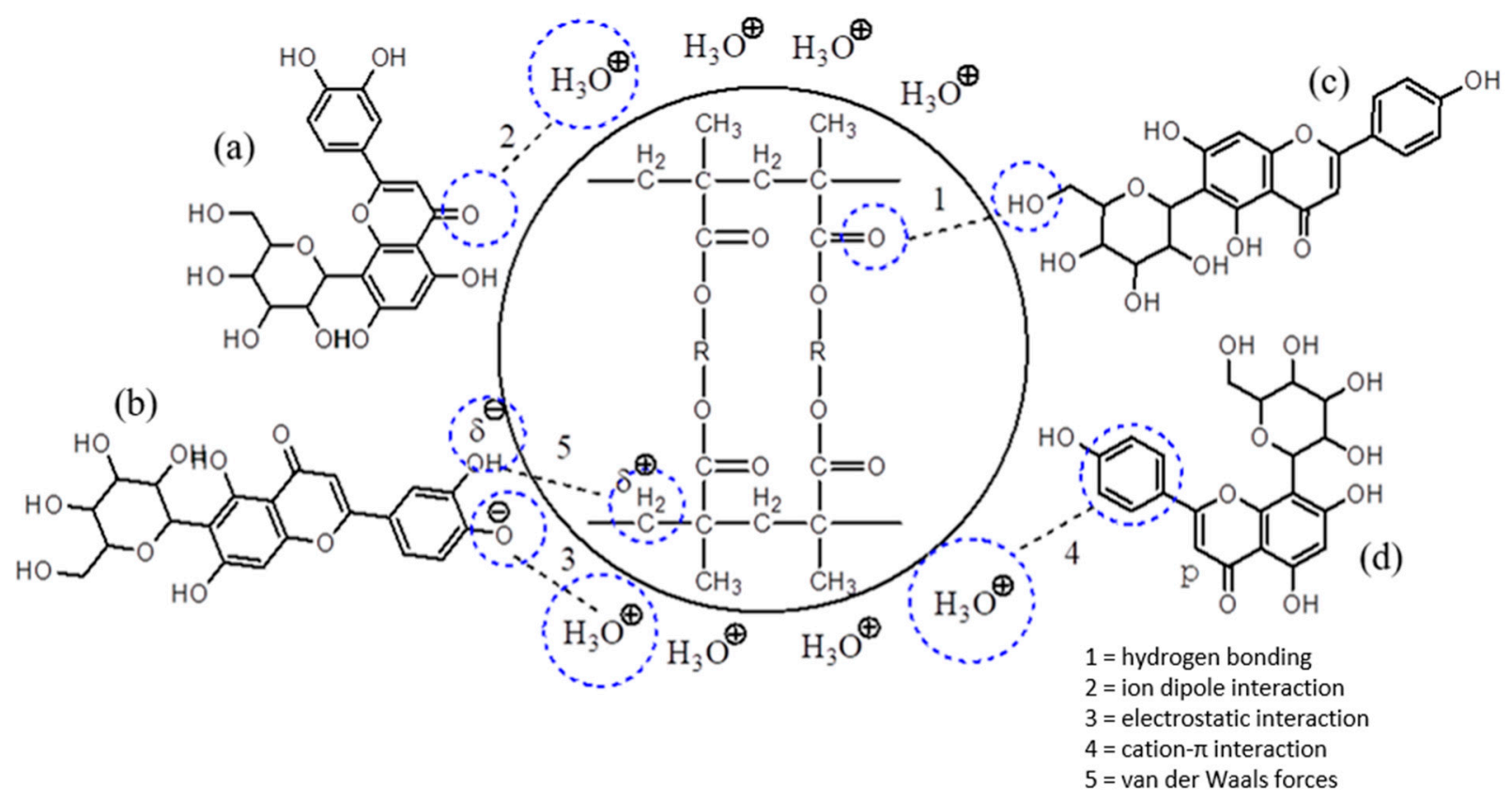

Figure 7. Schematic representation of the postulated interactions between targeted flavonoid C-glycosides for orientin (a), isoorientin (b), isovitexin (c), and vitexin (d) and the XAD7HP resin under acidic conditions.

The findings from both the isocratic and gradient elution experiments showed that isovitexin was enriched between 55- and 60-fold, while isoorientin, vitexin, and orientin were enriched by $20-25,15-20$ and 11-15-fold, respectively. This phenomenon could be 
due to strong hydrogen bonding interactions between the hydroxyl groups attached to the aglycones and the surface of the cross-linked polymeric resins $[9,19]$. The studied flavonoid $\mathrm{C}$-glycosides shared similar flavone aglycone with differences in the sugar moiety position, as shown in Figure 1A. It was previously reported that a flavonoid molecule with sugar moiety attached to it could reach approximately $2.0 \mathrm{~nm}$ in size [50], and with additional hydroxyl groups contributed by glucosides, this collectively enhanced the sorption process to the large pore size and moderately polar resin XAD7HP.

Moreover, in between isomeric compounds, isovitexin/vitexin had higher enrichment than isoorientin/orientin. This could be explained by the steric hindrance $[48,51,52]$. Referring to Figure 1A, vitexin isomers have one hydroxyl group bonded at $C-4^{\prime}$ (para position) of ring $\mathrm{B}$, whereas orientin isomers have two hydroxyl groups attached at $C$ $3^{\prime}$ (meta position) and $C-4^{\prime}$ (para position) of the same ring. Since the hydroxyl group is one of the para directing groups, attachment of these hydroxyl groups onto the para position lessened the steric hindrance, resulting in less repulsion between the groups and lastly assisting the interaction of these groups with the resin through hydrogen bonds. However, the addition of one hydroxyl group onto the $C-3^{\prime}$ position of the orientin isomers increased the steric hindrance, as the hydroxyl group was larger than the hydrogen atom, causing congestion that may have slowed down the interaction of the atom with the surface of resins.

\section{Conclusions}

The present study provides experimental data on the enrichment of the total flavonoid $C$-glycosides content via a process combining acid hydrolysis and adsorption and desorption on MARs. The XAD7HP resin showed the best sorption capacities. The enrichment of the flavonoid $C$-glycosides content of OPL extract was conducted at optimal conditions, where the leaf extract, prehydrolyzed with acid and adjusted to a $\mathrm{pH}$ of 5, was shaken at $298 \mathrm{~K}$ for a period of $24 \mathrm{~h}$ for static adsorption. The adsorption process of the target flavonoids on the XAD7HP resin could be well-described with the pseudo-second-order kinetic model. The equilibrium experimental data of the adsorption of isoorientin and orientin on the XAD7HP resin at $298 \mathrm{~K}$ were well fitted to the Langmuir isotherm model, while those of vitexin and isovitexin were well described by the Freundlich isotherm model. The enriched fractions recovered using the isocratic (with $95 \% \mathrm{EtOH}$ ) and gradient elution modes (with $40 \% \mathrm{EtOH}$ ) produced up to 60 -fold flavonoid enrichment with excellent antioxidant free radical scavenging activities. The enriched OPLAH contained isoorientin

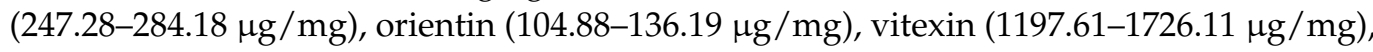
and isovitexin (13.03-14.61 $\mu \mathrm{g} / \mathrm{mg})$, as compared to OPLAH with isoorientin $(2.34 \mu \mathrm{g} / \mathrm{mg})$, orientin $(9.35 \mu \mathrm{g} / \mathrm{mg})$, vitexin $(84.11 \mu \mathrm{g} / \mathrm{mg})$, and isovitexin $(0.25 \mu \mathrm{g} / \mathrm{mg})$. Additionally, the enriched OPLAH also showed excellent antioxidant free radical scavenging activities compared with OPLAH, with $\mathrm{IC}_{50}$ values of $6.90-70.63 \mu \mathrm{g} / \mathrm{mL}$ and $44.58-200.00 \mu \mathrm{g} / \mathrm{mL}$, respectively. Strong hydrogen bonding may explain the efficient enrichment of the target flavonoid C-glycosides. The results indicated the combination of acid treatment and MARs could selectively and effectively enrich flavonoid $C$-glycosides from OPL. This study presents a simple, rapid, and efficient method for enriching the flavonoid C-glycoside content of oil palm leaf extract, a major type of agriculture waste, which has been underutilized. This method provides several potential applications, such as for further purification of major flavonoid C-glycosides as fine chemicals or pharmaceuticals or the use of the enriched fraction as bioactive ingredients in nutraceutical, cosmeceutical, and other healthcare or personal care products.

Supplementary Materials: The following are available online at https://www.mdpi.com/article/10 .3390/pr9040659/s1. Figure S1: Adsorption isotherms of isoorientin (A), orientin (B), vitexin (C) and isovitexin (D) present in OPLAH at $298 \mathrm{~K}$ on XAD7HP resin; Figure S2: (A) UHPLC chromatograms $(340 \mathrm{~nm})$ of OPLAH and OPLAH-enriched fractions obtained via isocratic and gradient elution desorption modes. (B) Compound confirmation using UHPLC-MS/MS analysis. 
Author Contributions: K.S. and M.S.C.Z. conceptualized and designed the experiments; K.S. provided the research materials; M.S.C.Z. performed the experiments and wrote the manuscript; K.S. and M.S.C.Z. analyzed the data; K.S. and C.Y.T. validated the data; K.S. and S.Y.L. edited the manuscript. All authors have read and agreed to the published version of the manuscript.

Funding: This research received no external funding.

Acknowledgments: The first author would like to thank Universiti Putra Malaysia for granting him a graduate research fellowship (GRF) scheme.

Conflicts of Interest: The authors declare no conflict of interest.

\section{References}

1. Whitmore, T.C. The Palms of Malaya; Longmans: Selangor, Malaysia, 1973.

2. Basiron, Y. Palm oil production through sustainable plantations. Eur. J. Lipid Sci. Technol. 2007, 109, 289-295. [CrossRef]

3. Malaysian Palm Oil Board (MPOB). Malaysian Oil Palm Industry Performance 2016 and Prospects for 2017. Available online: http: / / www.mpob.gov.my (accessed on 20 January 2019).

4. Malaysian Palm Oil Board (MPOB). Production of Oil Palm Products 2020. Available online: http://bepi.mpob.gov.my (accessed on 27 January 2021).

5. Be Sustainable Magazine. Malaysia's Biomass Potential. Available online: http://www.besustainablemagazine.com (accessed on 13 February 2021).

6. Owoyele, B.V.; Owolabi, G.O. Traditional oil palm (Elaeis guineensis Jacq.) and its medicinal uses: A review. Tang Humanit Med. 2014, 4, 1-8. [CrossRef]

7. Tahir, N.I.; Shaari, K.; Abas, F.; Parveez, G.K.A.; Ishak, Z.; Ramli, U.S. Characterization of apigenin and luteolin derivatives from oil palm (Elaeis guineensis Jacq.) leaf using LC-ESI-MS/MS. J. Agric. Food Chem. 2012, 60, 11201-11210. [CrossRef] [PubMed]

8. Xiao, J.; Capanoglu, E.; Jassbi, A.R.; Miron, A. Advance on the Flavonoid C-glycosides and Health Benefits. Crit. Rev. Food Sci. Nutr. 2016, 56, S29-S45. [CrossRef]

9. Zain, M.S.C.; Lee, S.Y.; Teo, C.Y.; Shaari, K. Adsorption and Desorption properties of total flavonoids from oil palm (Elaeis guineensis Jacq.) mature leaf on macroporous adsorption resins. Molecules 2020, 25, 778. [CrossRef]

10. Zain, M.S.C.; Jakariah, N.A.; Yeoh, J.X.; Lee, S.Y.; Shaari, K. Ultrasound-assisted extraction of polyphenolic contents and acid hydrolysis of flavonoid glycosides from oil palm (Elaeis guineensis Jacq.) leaf: Optimization and correlation with free radical scavenging activity. Processes 2020, 8, 1540. [CrossRef]

11. Zain, M.S.C.; Lee, S.Y.; Mad Nasir, N.; Fakurazi, S.; Shaari, K. Metabolite characterization and correlations with antioxidant and wound healing properties of oil palm (Elaeis guineensis Jacq.) leaflets via ${ }^{1} \mathrm{H}-\mathrm{NMR}-$ based metabolomics approach. Molecules 2020, 25, 5636. [CrossRef] [PubMed]

12. Zain, M.S.C.; Lee, S.Y.; Sarian, M.N.; Fakurazi, S.; Shaari, K. In vitro wound healing potential of flavonoid c-glycosides from oil palm (Elaeis guineensis Jacq.) leaves on 3t3 fibroblast cells. Antioxidants 2020, 9, 326. [CrossRef]

13. Mordor Intelligence. Flavonoid Market-Growth, Trends and Forecast (2020-2025). Available online: https://www. mordorintelligence.com (accessed on 20 July 2020).

14. Yang, X.; Wei, M.; Tian, H.; Liu, T.; Yang, L. Enrichment and purification of aucubin from Eucommia ulmoides ionic liquid extract using macroporous resins. Materials 2018, 11, 1758. [CrossRef] [PubMed]

15. Kim, J.; Kim, D.; Gwon, Y.J.; Lee, K.W.; Lee, T.S. Removal of sodium dodecylbenzenesulfonate by macroporous adsorbent resins. Materials 2018, 11, 1324. [CrossRef] [PubMed]

16. Tungmunnithum, D.; Drouet, S.; Kabra, A.; Hano, C. Enrichment in antioxidant flavonoids of stamen extracts from Nymphaea lotus L. using ultrasonic-assisted extraction and macroporous resin adsorption. Antioxidants 2020, 9, 576. [CrossRef]

17. Lin, L.; Zhao, H.; Dong, Y.; Yang, B.; Zhao, M. Macroporous resin purification behavior of phenolics and rosmarinic acid from Rabdosia serra (MAXIM.) HARA leaf. Food Chem. 2012, 130, 417-424. [CrossRef]

18. Du, H.; Wang, H.; Yu, J.; Liang, C.; Ye, W.; Li, P. Enrichment and purification of total flavonoid C-glycosides from Abrus mollis extracts with macroporous resins. Ind. Eng. Chem. Res. 2012, 51, 7349-7354. [CrossRef]

19. Liu, W.; Zhang, S.; Zu, Y.G.; Fu, Y.J.; Ma, W.; Zhang, D.Y.; Kong, Y.; Li, X.-J. Preliminary enrichment and separation of genistein and apigenin from extracts of pigeon pea roots by macroporous resins. Bioresour. Technol. 2010, 101, 4667-4675. [CrossRef]

20. Wang, X.; Liang, Y.; Zhu, L.; Xie, H.; Li, H.; He, J.; Pan, M.; Zhang, T.; Ito, Y. Preparative isolation and purification of flavone C-glycosides from the leaves of Ficus microcarpa L.f by medium-pressure liquid chromatography, high-speed countercurrent chromatography, and preparative liquid chromatography. J. Liq. Chromatogr. Relat. Technol. 2010, 33, 462-480. [CrossRef]

21. International Conference on Harmonization of Technical Requirment for Registration of Pharmaceuticals for Human Use, Validation of Analytical Procedures: Text and Methodology Q2 (R1); ICH: Geneva, Switzerland, 2005; Volume 7, pp. 1-5.

22. Zain, M.S.C.; Osman, M.F.; Lee, S.Y.; Shaari, K. UHPLC-UV /PDA method validation for simultaneous quantification of luteolin and apigenin derivatives from Elaeis guineensis leaf extracts: An application for antioxidant herbal preparation. Molecules 2021, 26, 1084. [CrossRef] 
23. Bhattacharya, A.K.; Venkobachar, C. Removal of Cadmium (II) by low cost adsorbents. J. Environ. Eng. 1984, 110, 110-122. [CrossRef]

24. Ho, Y.S.; McKay, G. Pseudo-second order model for sorption processes. Process Biochem. 1999, 34, 451-465. [CrossRef]

25. Guibal, E.; Milot, C.; Tobin, J.M. Metal-anion sorption by chitosan beads: Equilibrium and kinetic studies. Ind. Eng. Chem. Res. 1998, 37, 1454-1463. [CrossRef]

26. Langmuir, I. The adsorption of gases on plane surfaces of glass, mica and platinum. J. Am. Chem. Soc. 1918, 40, 1361-1403. [CrossRef]

27. Kammerer, J.; Carle, R.; Kammerer, D.R. Adsorption and ion exchange: Basic principles and their application in food processing. J. Agric. Food Chem. 2011, 59, 22-42. [CrossRef] [PubMed]

28. Hall, K.R.; Eagleton, L.C.; Acrivos, A.; Vermeulen, T. Pore and solid diffusion kinetics in fixed-bed adsorption under constant pattern conditions. Ind. Eng. Chem. Fundam. 1966, 5, 212-223. [CrossRef]

29. Taktak, F.; Ciğeroğlu, Z.; Öğen, Y.; Kirbaşlar, Ş.İ. Resin-loaded cationic hydrogel: A new sorbent for recovering of grapefruit polyphenols. Chem. Eng. Commun. 2018, 205, 1442-1456. [CrossRef]

30. Şahin, S.; Bilgin, M. Selective adsorption of oleuropein from olive (Olea europaea) leaf extract using macroporous resin. Chem. Eng. Commun. 2017, 204, 1391-1400. [CrossRef]

31. Sun, Y.; Yuan, H.; Hao, L.; Min, C.; Cai, J.; Liu, J.; Cai, P.; Yang, S. Enrichment and antioxidant properties of flavone C-glycosides from trollflowers using macroporous resin. Food Chem. 2013, 141, 533-541. [CrossRef]

32. Zhang, L.; Wu, T.; Xiao, W.; Wang, Z.; Ding, G.; Zhao, L. Enrichment and purification of total Ginkgo flavonoid O-glycosides from Ginkgo Biloba extract with macroporous resin and evaluation of anti-inflammation activities in vitro. Molecules 2018, $23,1167$. [CrossRef] [PubMed]

33. Huang, J.H.; Huang, K.L.; Wang, A.T.; Yang, Q. Adsorption characteristics of poly(styrene-co-divinylbenzene) resin functionalized with methoxy and phenoxy groups for phenol. J. Colloid Interface Sci. 2008, 327, 302-307. [CrossRef]

34. Wan, P.; Sheng, Z.; Han, Q.; Zhao, Y.; Cheng, G.; Li, Y. Enrichment and purification of total flavonoids from Flos Populi extracts with macroporous resins and evaluation of antioxidant activities in vitro. J. Chromatogr. B Anal. Technol. Biomed. Life Sci. 2014, 945-946, 68-74. [CrossRef]

35. Lorenc-Grabowska, E.; Gryglewicz, G. Adsorption of lignite-derived humic acids on coal-based mesoporous activated carbons. J. Colloid Interface Sci. 2005, 284, 416-423. [CrossRef] [PubMed]

36. Ayranci, E.; Hoda, N. Adsorption kinetics and isotherms of pesticides onto activated carbon-cloth. Chemosphere 2005, 60, 1600-1607. [CrossRef] [PubMed]

37. Chao, L.; Hong, Z.; Li, Z.; Gang, Z. Study on adsorption characteristic of macroporous resin to phenol in wastewater. Can. J. Chem. Eng. 2010, 88, 417-424. [CrossRef]

38. Liu, Y.; Bai, Q.; Lou, S.; Di, D.; Li, J.; Guo, M. Adsorption characteristics of (-)-epigallocatechin gallate and caffeine in the extract of waste tea on macroporous adsorption resins functionalized with chloromethyl, amino, and phenylamino groups. J. Agric. Food Chem. 2012, 60, 1555-1566. [CrossRef] [PubMed]

39. Lou, S.; Chen, Z.; Liu, Y.; Ye, H.; Di, D. Synthesis of functional adsorption resin and its adsorption properties in purification of flavonoids from Hippophae rhamnoides L. leaves. Ind. Eng. Chem. Res. 2012, 51, 2682-2696. [CrossRef]

40. Wang, R.; Peng, X.; Wang, L.; Tan, B.; Liu, J.; Feng, Y.; Yang, S. Preparative purification of peoniflorin and albiflorin from peony rhizome using macroporous resin and medium-pressure liquid chromatography. J. Sep. Sci. 2012, 35, 1985-1992. [CrossRef] [PubMed]

41. Cao, S.Q.; Pan, S.Y.; Yao, X.L.; Fu, H.F. Isolation and Purification of Anthocyanins from Blood Oranges by Column Chromatography. Agric. Sci. China 2010, 9, 207-215. [CrossRef]

42. Wu, S.; Wang, Y.; Gong, G.; Li, F.; Ren, H.; Liu, Y. Adsorption and desorption properties of macroporous resins for flavonoids from the extract of Chinese wolfberry (Lycium barbarum L.). Food Bioprod. Process. 2015, 93, 148-155. [CrossRef]

43. Koch, W.; Kukuła-Koch, W.; Czop, M.; Helon, P.; Gumbarewicz, E. The role of extracting solvents in the recovery of polyphenols from green tea and its antiradical activity supported by principal component analysis. Molecules 2020, 25, 2173. [CrossRef]

44. Abdul-Hamid, N.A.; Mustaffer, N.H.; Maulidiani, M.; Mediani, A.; Ismail, I.S.; Tham, C.L.; Shadid, K.; Abas, F. Quality evaluation of the physical properties, phytochemicals, biological activities and proximate analysis of nine Saudi date palm fruit varieties. J. Saudi Soc. Agric. Sci. 2010, 19, 151-160. [CrossRef]

45. Sinjman, P.W.; Joubert, E.; Ferreira, D.; Li, X.C.; Ding, Y.; Green, I.R.; Gelderblom, W.C. Antioxidant activity of the dihydrochalcones aspalathin and nothofagin and their corresponding flavones in relation to other rooibos (Aspalathus linearis) flavonoids, epigallocatechin gallate, and Trolox. J. Agric. Food Chem. 2009, 57, 6678-6684. [CrossRef]

46. Gerhäuser, C. Phenolic Beer Compounds to Prevent Cancer. Beer in Health and Disease Prevention; Elsevier: London, UK, 2009; pp. 669-684.

47. Khole, S.; Panat, N.A.; Suryawanshi, P.; Chatterjee, S.; Devasagayam, T.; Ghaskadbi, S. Comprehensive assessment of antioxidant activities of apigenin isomers: Vitexin and isovitexin. Free Radic. Antioxid. 2016, 6, 155-166. [CrossRef]

48. Wu, X.; Liu, Y.; Huo, T.; Chen, Z.; Liu, Y.; Di, D.; Guo, M.; Zhao, L. Multiple interactions on macroporous adsorption resins modified with ionic liquid. Colloids Surfaces A Physicochem. Eng. Asp. 2015, 487, 35-41. [CrossRef]

49. Havsteen, B.H. The biochemistry \& medical significance of the flavonoids. Pharmacol. Ther. 2002, 96, 67-202. [PubMed] 
50. Li, J.; Chase, H.A. Development of adsorptive (non-ionic) macroporous resins and their uses in the purification of pharmacologically-active natural products from plant sources. Nat. Prod. Rep. 2010, 27, 1493. [CrossRef] [PubMed]

51. Xiao, J. Dietary flavonoid aglycones and their glycosides: Which show better biological significance? Crit. Rev. Food Sci. Nutr. 2017, 57, 1874-1905. [CrossRef]

52. Cao, H.; Chen, X. Structures required of flavonoids for inhibiting digestive enzymes. Anticancer Agents Med. Chem. 2012, 12, 929-939. [CrossRef] 